\title{
Inclusão e deficiência intelectual: escola especial e comum sob a óptica dos próprios alunos
}

\section{Inclusion and intellectual disability: special and common schools under the point of view of students themselves}

\author{
Ana Paula Pacheco Moraes Maturana* \\ Enicéia Gonçalves Mendes**
}

\begin{abstract}
RESUMO
Considerando que, sob o estandarte da inclusão, transferências escolares entre escola especial e comum vêm ocorrendo em todo o território nacional, faz-se necessário investigar como os alunos públicos dessas percebem esse processo, uma vez que a literatura alerta sobre a ausência da participação do aluno sobre as decisões a respeito de sua escolarização. $\mathrm{O}$ estudo tem por objetivo investigar a concepção dos alunos com deficiência intelectual (DI) sobre a escola especial e a escola regular, tendo como cenário suas transferências escolares: da escola especial para a escola comum ou vice-versa. Trata-se de uma pesquisa descritiva com delineamento de múltiplos casos que envolveu o estudo de cinco casos de alunos com DI que foram transferidos. Os instrumentos utilizados para coleta de dados foram o Procedimento Desenho-Estória com os alunos e complementarmente entrevistas com familiares. A análise dos dados permitiu identificar que os alunos atribuíram à escola especial o papel de acolhimento e cuidado e, para a escola comum, um local de aprendizagem e conhecimento, ficando claro que para esses existem duas formas distintas de escolarização, cada uma com seus prós e contras. A análise dos resultados evidencia que o estudo alcançou seus
\end{abstract}

\section{DOI: $10.1590 / 0104-4060.50516$}

* Universidade Estadual Paulista Júlio de Mesquita Filho. Bauru, São Paulo, Brasil. Campus Bauru. Av. Eng. Luís Edmundo Carrijo Coube, 14-01. Núcleo Res. Pres. Geisel. CEP: 17033-360. E-mail: paula.psico@hotmail.com

** Universidade Federal de São Carlos. São Carlos, São Paulo, Brasil. Rodovia Washington Luís, s/n. CEP: 13565-905. E-mail: eniceia.mendes@gmail.com 
objetivos e trouxe implicações práticas, políticas e científicas relacionadas à escolarização do aluno com DI, principalmente ao dar voz ao próprio aluno alvo da transferência escolar, no caso, o aluno com DI.

Palavras-chave: Educação especial. Alunos. Deficiência intelectual. Inclusão.

\begin{abstract}
Considering that under the banner of inclusion school transfers between special and common schools have been taking place throughout national territory, it is necessary to investigate how the public students of these schools perceive this process, since the literature warns about the absence of student participation on the decisions about their schooling process. This work aimed to investigate the thoughts of students with intellectual disabilities (ID) on special and regular schools, taking their school transfers as a scenario, be this transfer from the special to the common school or vice versa. It is a descriptive research with multiple case design that involved the study of five cases of ID students who were transferred. The instruments used for data collection were the Drawing-and-Story procedure with the students and complementary interviews with family members. The analysis of the data allowed us to identify that the students assigned to the special school the role of reception and care, and to the common school a place of learning and knowledge, with awareness that these are two distinct forms of schooling, each with its pros and cons. The analysis of the results shows that the study reached its objectives and brought practical, political and scientific implications related to the schooling of the students with ID, especially when giving voice to the target of the school transfer.
\end{abstract}

Keywords: Special Education. Students. Intellectual disability. Inclusion.

A inclusão vem se apresentando como uma temática cada vez mais discutida no ambiente escolar, com leis e diretrizes voltadas à inclusão do aluno público, alvo da educação especial, tais como a Política Nacional de Educação Especial na Perspectiva da Educação Inclusiva (BRASIL, 2008), os regulamentos e normas sobre a implantação do Atendimentos Educacional Especializado e das Salas de Recursos Multifuncionais (BRASIL, 2008, 2011) e a Lei Brasileira de Inclusão da Pessoa com Deficiência (BRASIL, 2015). Nesse sentido, por conta da presença dessa temática no cotidiano escolar, os profissionais da escola têm, de alguma forma, contato com a inclusão escolar em relação às ideias e aos ideais referentes ao seu conceito. Muitas vezes o contato com o conceito não ocorre de maneira e com o aprofundamento necessários. Assim, por tratar-se de 
um assunto que envolve a transformação de paradigmas, sendo acima de tudo um "[...] princípio ideológico em defesa da igualdade de direitos e do acesso às oportunidades para todos os cidadãos [...]" (OMOTE, 2003, p. 154). Nos dias de hoje, nas realidades escolares, verifica-se que o "fazer" da inclusão traduz-se numa multiplicidade de práticas permeadas pelas subjetividades desses profissionais da escola (professores, coordenadores, diretores). Em outras palavras, verifica-se que na prática escolar o conceito e a práxis da inclusão são permeados pelos entendimentos que os profissionais da escola têm sobre seu público alvo, formas de ensino e aprendizagem, formas de encaminhamentos e de avaliações, o que pode resultar em um descompasso entre teoria, prática e política.

Mendes (2006) afirma que tempos atrás a segregação de alguns alunos era baseada na crença de que estes seriam melhor atendidos em suas necessidades educacionais se ensinados em ambientes separados. Nesse sentido, observou-se, principalmente nos anos 1980, o encaminhamento de alunos das classes comuns para classes especiais e, em alguns casos, para instituições e/ou escolas especializadas. Atualmente verifica-se que, em algumas realidades, as transferências escolares de alunos com deficiência intelectual (DI) são realizadas tanto da escola especial para a escola comum como vice-versa, caminhando-se para um retrocesso político, social e educacional. Isso se deve ao fato de que muitas dessas transferências são realizadas de maneira arbitrária e desconsiderando pressupostos legais, sendo por vezes justificadas pelos comportamentos do próprio aluno e sem nenhuma relação com o processo escolar (GARCIA, 2004; PALMA; DIAS, 2005).

Sendo assim, muitas são as dúvidas e dissensos sobre a inclusão escolar no caso de alunos com DI. Primeiramente há que se considerar que o grupo de alunos com DI é bastante heterogêneo, compreendendo desde alunos com dificuldades de escolarização, que somente são identificados quando ingressam na escola, até indivíduos com limitações em vários domínios, identificados precocemente. Considerando o grupo de alunos com DI como um todo, não há evidências empíricas inequívocas de que todos eles possam se beneficiar da escolarização em classe comum, e a prova disso é o fato de que a maioria dos países com políticas mais antigas de inclusão escolar mantém as duas possibilidades de escolarização para estudantes com DI: escolas comuns e especiais (MATURANA; MENDES, 2015).

Tendo em vista toda essa problemática como pano de fundo das transferências escolares, o presente estudo tem como intuito contribuir para a discussão do processo de inclusão escolar do aluno com DI. À medida que dá voz aos principais atores envolvidos nesse processo, os alunos, o estudo pretende demonstrar a heterogeneidade dessa população, a importância de considerar seus desejos, aspirações escolares e as relações humanas que estabelecem no ambiente 
escolar quanto fatores relevantes para se pensar na prática da inclusão escolar. Desse modo, destaca-se a relevância social do presente trabalho. A relevância científica e acadêmica do presente estudo fica, entre outros motivos, por conta da originalidade do mesmo, por dar voz aos alunos e considerar o aluno com DI sujeito ativo e participativo desse processo.

A literatura da área aponta que a exclusão do aluno do processo de transferência escolar e até mesmo do encaminhamento para o Atendimento Educacional Especializado é prática habitual nos ambientes escolares (DIAS, 2012; ANTUNES, 2012). Os efeitos advindos da simples colocação, ou matrícula do aluno com DI, na sala de aula comum do ensino regular, certamente são problemáticos e na maioria das vezes negativos para alunos, familiares e educadores. Em relação ao aluno, essa prática pode prejudicá-lo em diversos âmbitos, levando ao surgimento ou à intensificação de sentimentos de ansiedade, frustrações recorrentes, baixa autoestima e isolamento social (MENDES; CAPELLINI, 2007). Quando a transferência escolar acontece à revelia dos desejos do próprio aluno, este pode vivenciar situações emocionalmente desfavoráveis no ambiente escolar (CUNHA; ROSSATO, 2015), tais como o bullying e o sentimento de não-pertencer (MOSCARDINI, 2011). Contudo, quando o processo de inclusão escolar envolve a mudança de práticas pedagógicas estratificadas e os professores e gestores consideram a subjetividade dos alunos no planejamento do ensino, isto propicia aos alunos oportunidades importantes que podem resultar em ganhos acadêmicos e sociais consideráveis (PLETSCH; GLAT, 2012; CUNHA; ROSSATO, 2015). Dessa forma, o objetivo do presente trabalho foi investigar a concepção dos alunos com deficiência intelectual sobre a escola especial e a escola regular, tendo como cenário suas transferências escolares, tanto da escola especial para a escola comum e vice-versa.

\section{Método}

Trata-se de uma pesquisa descritiva com delineamento de múltiplos casos. A pesquisa obteve aprovação do Comitê de Ética e da Comissão Nacional de Ética em Pesquisa e da Secretaria Municipal de Ensino, órgãos ao quais foi submetida. Foram observadas as exigências implicadas na Resolução CONEP $\mathrm{n}^{\mathrm{o}} 466$, de 12 de dezembro de 2012. 


\section{Participantes e local}

A pesquisa foi realizada em uma cidade do centro-oeste paulista. Participaram da pesquisa cinco alunos (Tabela 1) com DI mediante prévia autorização dos responsáveis, sendo que todos os alunos participantes passaram por transferências escolares.

\section{TABELA 1 - CARACTERIZAÇÃO DOS ALUNOS COM DI PARTICIPANTES DA PESQUISA}

\begin{tabular}{|l|l|l|l|l|l|l|}
\hline Nome & Idade & Sexo & $\begin{array}{l}\text { Tempo na } \\
\text { Escola Especial }\end{array}$ & $\begin{array}{l}\text { Tempo na } \\
\text { Escola Comum }\end{array}$ & $\begin{array}{l}\text { Escola } \\
\text { Atual }\end{array}$ & $\begin{array}{l}\text { Frequenta } \\
\text { SRM }^{1}\end{array}$ \\
\hline Saulo & 10 anos & M. & 5 anos & 1 ano & Comum & Sim \\
\hline Flávia & 13 anos & F. & 6 anos & 4 meses & Especial & Não \\
\hline Fábio & 18 anos & M. & 3 anos & 9 anos & Especial & Não \\
\hline Sofia & 8 anos & F. & 1 ano & 3 anos & Comum & Não \\
\hline Fabíola & 14 anos & F. & 5 anos & 4 anos & Comum & Não \\
\hline
\end{tabular}

Os nomes atribuídos são fictícios. Os dados foram coletados nas escolas e residências dos alunos conforme conveniência do participante. Para obtenção dos recursos adicionais para compreensão das transferências escolares, realizaram-se entrevistas com os familiares.

\section{Instrumento}

Para os alunos, o instrumento eleito foi uma adaptação do Procedimento de Desenhos-Estórias (D-E), de Walter Trinca (2013). Tal técnica foi selecionada por apresentar inúmeras vantagens: possibilidade de investigação de conteúdo subjetivo e inconsciente, adaptabilidade às necessidades do examinando, concisão na focalização e no material obtido, pela possibilidade de ser aplicado com pessoas de ambos os sexos, todas as faixas etárias, qualquer nível mental, socioeconômico e cultural (TRINCA, 2013). Por conta dos objetivos da pesquisa, os alunos foram convidados a realizar uma série de dois desenhos, seguidos de suas respectivas estórias. Inicialmente, solicitou-se que o desenho e a estória

1 Como se pode observar na Tabela 1, o aluno Saulo frequenta a Sala de Recurso Multifuncional (SRM) no contraturno na mesma escola que estuda atualmente. As alunas Sofia e Fabíola, apesar de estudarem em salas de aula regulares do ensino comum, não frequentavam a SRM. De acordo com a mãe de Sofia, esta frequentou a SRM por um ano e após esse período teve "alta" (sic), não precisando mais comparecer para atendimento na SRM. No caso dos demais alunos, os pais não souberam explicar o motivo dos alunos não frequentarem a SRM. 
contada fossem da escola atual. Após seu término, o aluno recebeu instruções para a realização de desenho e estória sobre sua escola anterior (escola especial ou comum, dependendo do caso). Alguns alunos tiveram bastante dificuldade motora para desenhar, mesmo assim o desenho funcionou como um disparador para a estória que seria contada e/ou para frases e conversas que o aluno teria durante a aplicação do Procedimento D-E. Para os familiares dos alunos, utilizou-se uma entrevista semiestrutura.

\section{Coleta e análise de dados}

As condições tanto de aplicação do Procedimento D-E como de sua correção seguiram as normas prescritas em seu manual, o que permitiu a identificação de elementos subjetivos sobre as transferências escolares. Como muitos participantes tiveram dificuldades para a realização do desenho e manejo do lápis, a análise da estória seguida a cada desenho foi fundamental para a compreensão de como esse processo afetou os alunos. Em relação às entrevistas com os familiares, utilizou-se a técnica de análise de práticas discursivas, Mapas de Associação de Ideias (SPINK, 2010). Contudo, como o recorte principal do trabalho é a participação dos alunos, os dados decorrentes das análises das entrevistas são considerados dados complementares e apresentados de forma a elucidar eventos e características das transferências escolares dos alunos.

\section{Resultados e discussões}

A análise geral dos desenhos e das respostas às questões do Procedimento D-E possibilitou a criação de dois eixos de análise.

\section{A escola especial na perspectiva dos alunos com DI}

A análise inicia-se com a participação de Saulo. Nesse caso, para comodidade da família, a coleta foi realizada em uma sala cedida pela escola especial, pois era mais próxima de sua residência. Saulo apresentou dificuldades para compreender as instruções dadas pela pesquisadora. Depois de um tempo, pegou o lápis e o colocou sob a folha de papel em branco. Quando solicitado para fazer o desenho da escola especial, Saulo disse não querer porque estava cansado. Tal dado pode ser entendido como uma resistência, visto que o aluno estava no período de férias. Estimulado a falar sobre como era a instituição especializada 
e contar uma estória, o aluno disse que gostava do motorista da escola, que o buscava todos os dias em sua casa, de sua professora e da cozinheira. Os alunos tomavam café da manhã e almoçavam todos os dias na instituição especializada. Saulo verbalizou várias vezes que gostaria de ver sua professora. Explicou-se que ela não estava lá, pois naquele dia não havia aula. Saulo estudou durante cinco anos na instituição, sendo que nos últimos anos frequentava a mesma sala, com os mesmos colegas e a mesma professora. Foi possível observar que, para o aluno, a instituição especializada guarda um aspecto afetivo e carinhoso, como um local de cuidado. De acordo com sua mãe, Saulo sente saudades dos profissionais e colegas da instituição especializada. A realização da coleta de dados nessa instituição provavelmente suscitou o aparecimento de memória afetiva sobre os anos que estudara lá, o que pode explicar o porquê de o aluno solicitar para ver a professora, a cozinheira e o motorista. No período da entrevista, fazia um ano que Saulo estudava na escola comum.

A segunda participante, Flávia, recusou-se a desenhar, dizendo que não conseguiria, que iria "sair feio" (sic). Apesar do rapport e do acolhimento da pesquisadora, a aluna não quis desenhar. Logo, solicitou-se para ela contar uma estória sobre a escola. Flávia disse que não sabia contar estórias, preferindo contar sobre seu dia a dia na instituição especializada. "As aulas de educação física. Gosto delas e do professor. A gente brinca muito. Não gosto do L. [aluno de sua sala], ele é chato, $W$ [outro aluno] também. Gosto mais ou menos de estudar. Gosto de ir na psicóloga, mas não gosto do médico e de tomar remédio" (Flávia).

De acordo com os familiares, Flávia não tinha amigos da mesma idade, pois os agredia fisicamente. Os alunos citados em seu relato (L. e W.) sempre rivalizavam com a aluna, disputando a atenção da professora ou dos profissionais técnicos durante alguma atividade, o que acabava muitas vezes em briga e agressão física entre eles. Flávia relatou gostar das aulas de educação física, pois nelas saía da sala de aula e ia brincar no parquinho. Para a aluna, a instituição especializada parecia representar um lugar de possibilidades: de brincar, correr, fazer suas traquinagens de criança. Flávia também via a escola especial como um local sem obrigações rígidas, diferentemente da escola comum. A instituição especializada é vista pela aluna como um lugar prazeroso, onde era aceita, pelo menos pelos adultos, e onde suas vontades eram satisfeitas: "Eu gosto de estudar aqui, eu faço o que eu quero aqui" (Flávia sobre a instituição especializada).

Solicitado a desenhar sobre a escola especial, o terceiro participante, Fábio, perguntou o que era para desenhar. Estimulado a desenhar o que quisesse, o aluno dá início ao primeiro desenho (Figura 1). O traçado do desenho foi feito de maneira muito sútil, fraca, sendo que após a digitalização foi necessário alterar o contraste quatro vezes para que ele pudesse ser visualizado. 
FIGURA 1 - DESENHO DE FÁBIO SOBRE A ESCOLA ESPECIAL

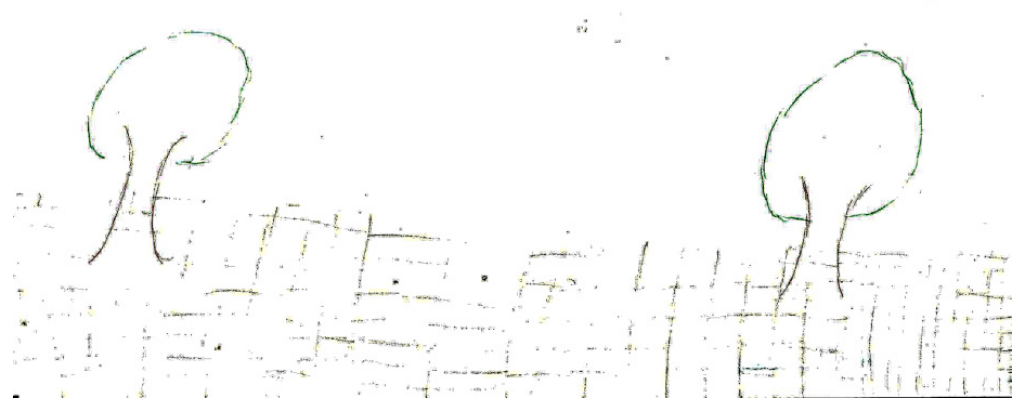

FONTE: acervo da pesquisa realizada.

Nota-se traços infantilizados e hesitantes. O medo da reprovação e do erro são constantes. Quando pegava no lápis, olhava para a pesquisadora solicitando aprovação: “É assim? Está certo?” (Fábio). No impedimento da pesquisadora se manifestar por conta de aspectos técnicos relativos à aplicação do Procedimento D-E, Fábio seguia desenhando. O aluno deu o título para o desenho com o nome da instituição especializada. Instigado a contar uma estória, o aluno disse não saber fazer estórias. Sobre os elementos do desenho, Fábio afirmou que fez as árvores do parquinho e a grade do portão de entrada da escola.

Mais uma vez o parquinho da escola surge no relato do aluno. Por ser um espaço com árvores, balanços e brinquedos, parece ser o local preferido dos alunos. Entre dois elementos que representam o parquinho (as árvores), Fábio desenha as grades da escola, representando segurança e contenção. Muito tímido, Fábio relatou que gostava dos colegas, menos de alguns, por estes serem violentos. Os colegas que Fábio temia tinham 10 e 11 anos, respectivamente. Fábio afirmou gostar de duas professoras. Uma deu aula para ele quando ele chegou na instituição especializada e a outra é sua professora atual.

No período de férias, a instituição especializada promovia um programa com atividades lúdicas e passeios em áreas de lazer, zoológico, cinema e ranchos com os alunos, contudo, participavam apenas alunos com bom comportamento 
durante o ano. Como a maioria dos alunos era de nível socioeconômico baixo, essa muitas vezes era a única oportunidade de conhecer outras cidades e fazer passeios. Pelo bom comportamento, Fábio afirmou que todo ano participava dos passeios. De acordo com seu relato, esse é um dos motivos que fizeram com que o aluno gostasse de estudar na escola especial.

Logo, é possível inferir que para Fábio a escola especial representava um local seguro, no qual suas professoras importavam-se com ele e lhe davam atenção. De acordo com o relato do aluno, a instituição também possibilitou que ele trabalhasse no período contrário, pois a diretora conseguiu um emprego para ele em um supermercado da cidade. Relatou que isso o deixava feliz e realizado, pois todos os moços de sua idade também trabalhavam. Percebe-se aqui que a oportunidade de poder trabalhar, como assim o fazem os pares de mesma idade, criou em Fábio um sentimento de competência, nunca experimentado antes, pois estava acostumado as chacotas sobre não conseguir aprender a ler e a escrever. Para o aluno, isso compensou qualquer possível ônus advindo da transferência tardia para uma escola especial.

Em relação ao desenho de Sofia, quarta participante, este é fundamentalmente formado por traços e garatujas, sem formas definidas (Figura 2). O desenho apresenta um grande número de itens e a escolha foi pelas cores mais fortes e escuras, como preto, marrom e azul escuro.

\section{FIGURA 2 - DESENHO DE SOFIA SOBRE A ESCOLA ESPECIAL}

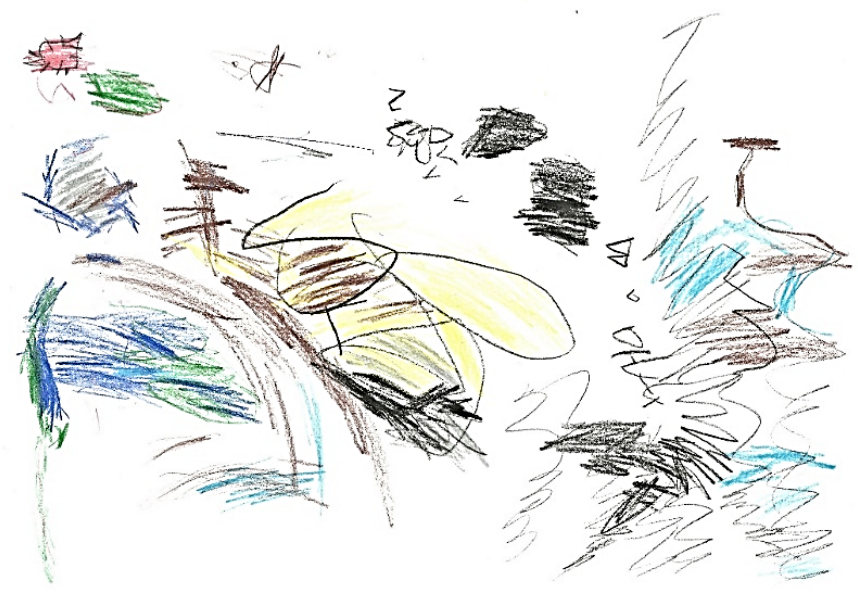

FONTE: acervo da pesquisa realizada. 
Solicitada a contar uma estória, Sofia relatou lembrar apenas do parquinho e de como gostava de brincar lá. Não soube falar sobre seus colegas ou professores. "Tem parquinho. O resto não lembro direito" (Sofia). A aluna apresentou dificuldade para comunicar-se, expressando-se mais por gesticulações e expressões faciais e corporais indicativas de acordo ou desacordo. Considerando que a aluna saiu com pouca idade (com 5 anos) da sala de estimulação, na instituição especializada, e foi para a escola comum, suas recordações da escola especial eram de um lugar lúdico, de muita brincadeira. Sofia não soube dar mais informações sobre a instituição ou os profissionais e colegas que conhecera lá.

Com Fabíola, quinta participante, a análise do Procedimento D-E foi diferente dos demais. Bem articulada e expressando-se bem, a adolescente de 14 anos realizou os desenhos e contou as estórias sem dificuldades. Indagada para desenhar algo sobre sua escola, Fabíola disse que gostaria de desenhar a própria escola.

\section{FIGURA 3 - DESENHO DE FABÍOLA SOBRE A ESCOLA ESPECIAL}

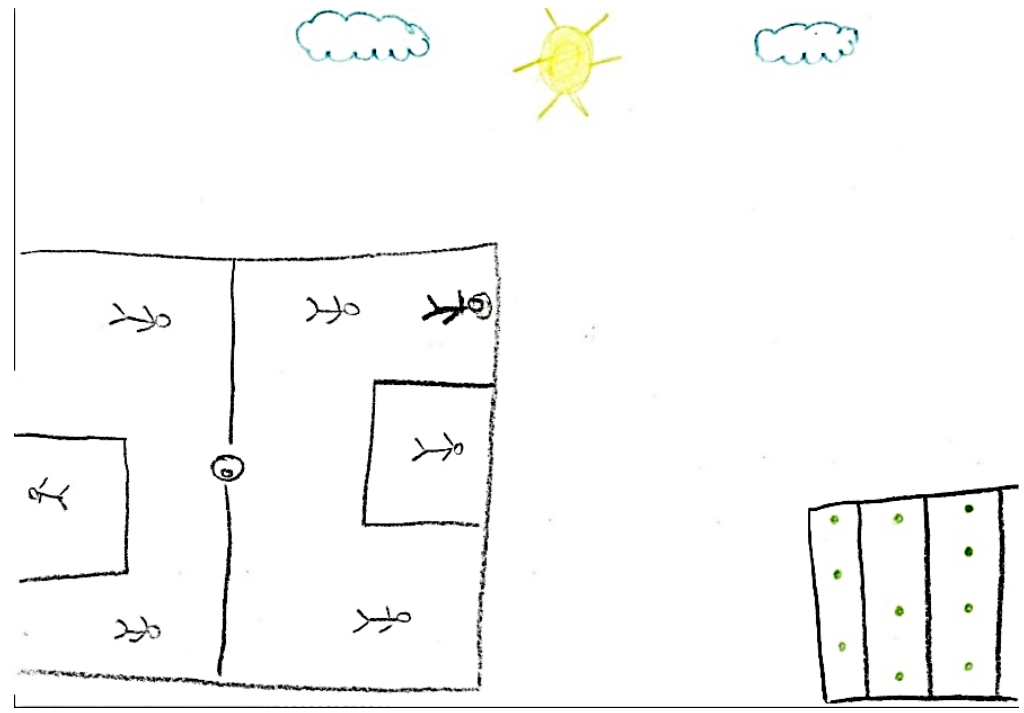

FONTE: acervo da pesquisa realizada.

No desenho (Figura 3) são representadas, à esquerda, a quadra de esportes que fica ao fundo da escola. Na quadra, ela e seus amigos estão jogando uma partida de futebol. A aluna é a figura humana com traços mais fortes, próxima à trave do lado direito e superior do campo desenhado. Na direita tem-se a horta que ficava atrás de sua sala de aula. Os pontos verdes representam as verduras 
plantadas. Durante o desenho, a aluna afirmou ter brincado nessa quadra várias vezes. Acima, vê-se sol e nuvens, fazendo referência a um dia ensolarado e feliz. Após o desenho, tem início a estória. Título da estória dado pela aluna: "Uma estória legal":

Era uma vez, eu e o professor de educação física, minha irmã e os outros meninos. Eu esqueci o nome deles, mas eu lembro deles, de vista. Nós fomos para a quadra e depois nós fomos plantar alface e ver os animais. Fomos jogar bola depois. Tinha pônei e galinha...um monte de coisa tinha. Eu lembro de tudo. (Fabíola).

Na estória, Fabíola faz referência aos aspectos externos a sua sala de aula, como quadra, horta, animais da área de equoterapia e as galinhas que ficavam na rua ao lado da escola. Mais uma vez, são abordados os aspectos lúdicos das atividades na instituição especializada. Sendo assim, o desenho e a estória de Fabíola endossam o que os outros participantes trouxeram em seus relatos. Outro aspecto relevante é a preferência dos alunos pelas aulas de educação física quando na escola especial.

\section{A escola comum na perspectiva dos alunos com DI}

Mais uma vez, a apresentação da análise tem início com o aluno Saulo. Solicitado a realizar um desenho sobre a escola comum, o aluno realizou a escrita de seu primeiro nome em letras grandes no canto esquerdo e superior da folha de sulfite. A fim de preservar sua identidade, o desenho não será apresentado. O aluno escreveu seu nome na folha e disse: "Já sei escrever meu nome, olha aqui" (Saulo). Era visível a felicidade de Saulo ao reconhecer as letras e saber escrever seu nome. Apesar da dificuldade em expressar-se, é possível inferir que Saulo estava bastante satisfeito em estudar na escola comum. Para o aluno, a escola comum é vista como um local de aprendizado da leitura e da escrita e vem lhe proporcionando satisfações pessoais por conta disso.

A participante Flávia não realizou nenhum dos dois desenhos e estórias. Sobre o tempo que estudou na escola comum, disse não se lembrar. Tal dado é justificado pelo fato da aluna ter permanecido apenas quatros meses no ensino regular. Sua transferência escolar foi bastante conflituosa, já que não foi tarefa fácil encontrar uma escola que a aceitasse. A instituição especializada foi o único local que permaneceu com a aluna por mais tempo. Expulsa de projetos da prefeitura (música) e de frequentar a igreja ("não ficava quieta", avó de Flávia), o 
único local que a acolheu, e que continuava acolhendo Flávia, foi essa instituição especializada. Mesmo assim, Flávia disse que pretende um dia estudar no ensino regular, chamando a escola comum de "escola grande". Parece que para a aluna, a permanência na instituição especializada é uma etapa necessária para um dia vir a frequentar o ensino regular: "Um dia eu estudo na escola grande" (Flávia).

Em relação a Fábio, solicitado a fazer o desenho sobre a escola comum, o aluno afirmou não se lembrar de como era lá, recusando-se a fazer o desenho. Sobre sua escola antiga, disse que tinha amigos, mas que eles riam dele. "Eles riam porque eu não lia" (Fábio). Visivelmente incomodado, mexendo-se na cadeira, Fábio disse não se lembrar de mais nada de lá, nem mesmo dos professores, apesar de ter estudado durante nove anos naquela escola. A resistência de Fábio para desenhar e falar sobre os alunos na escola comum era evidente. A partir de seu relato, foi possível notar que sua trajetória na escola comum deixou algumas marcas, como a rejeição, as zombarias dos colegas de classe e da escola e o bullying por conta de suas dificuldades, dificuldades de relacionamento e timidez.

$\mathrm{O}$ desenho de Sofia referente à escola comum segue o mesmo padrão do que a aluna fez sobre a escola especial. Novamente, como é possível notar, o desenho de Sofia não apresenta estrutura. Portanto, os dados sobre seus sentimentos e percepções sobre sua inclusão foram por meio da estória após o desenho. Quando solicitada para dar um título, Sofia relatou não saber.

\section{FIGURA 4 - DESENHO DE SOFIA SOBRE A ESCOLA COMUM}

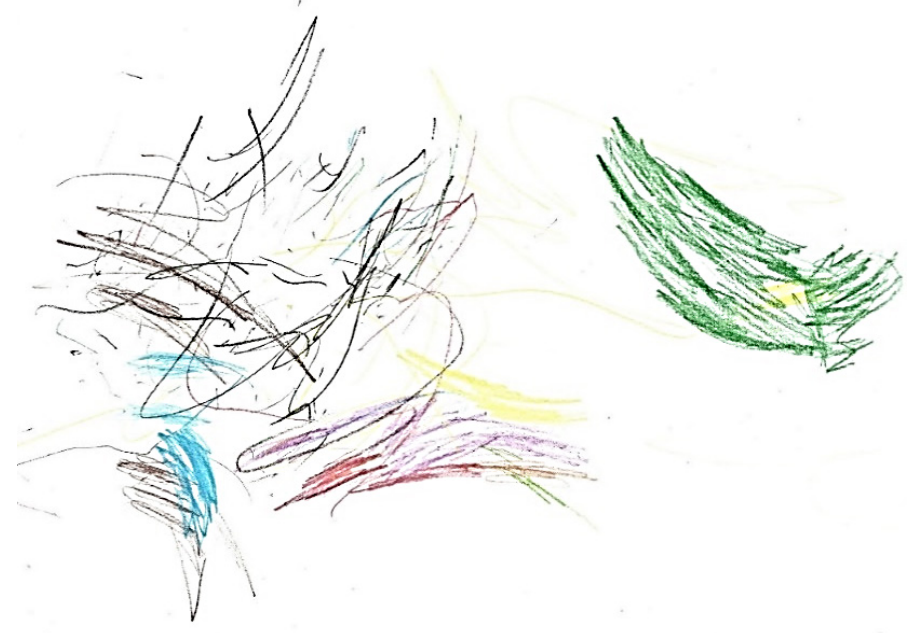

FONTE: acervo da pesquisa realizada. 
Na Figura 4, sobre a escola comum, é possível notar que a aluna escolheu cores mais alegres e vibrantes para a realização do desenho, como rosa, verde e amarelo. Estimulada a falar sobre sua escola atual (comum), Sofia disse que sua escola era grande e tinha muitas coisas. A criança relatou gostar de estudar em sua escola: "Lá é legal. Tem letras, lápis..." (Sofia). A participante relatou que alguns colegas riem dela e que ela não gosta disso, verbalizando um efusivo "NÃO GOSTO DISSO!" durante a conversa. Sobre sua escola atual, a aluna relacionou fatos como "estudar" e "aprender", vendo o ambiente como um local mais sério, de aprendizagem.

Já Fabíola utilizou as mesmas quatro cores do desenho anterior para colorir: amarelo, azul, verde e preto. Seu traçado é forte e rígido. A coloração do prédio da escola começou intensa, mas foi esmaecendo conforme avançava no desenho (Figura 5).

FIGURA 5 - DESENHO DE FABÍOLA SOBRE A ESCOLA COMUM

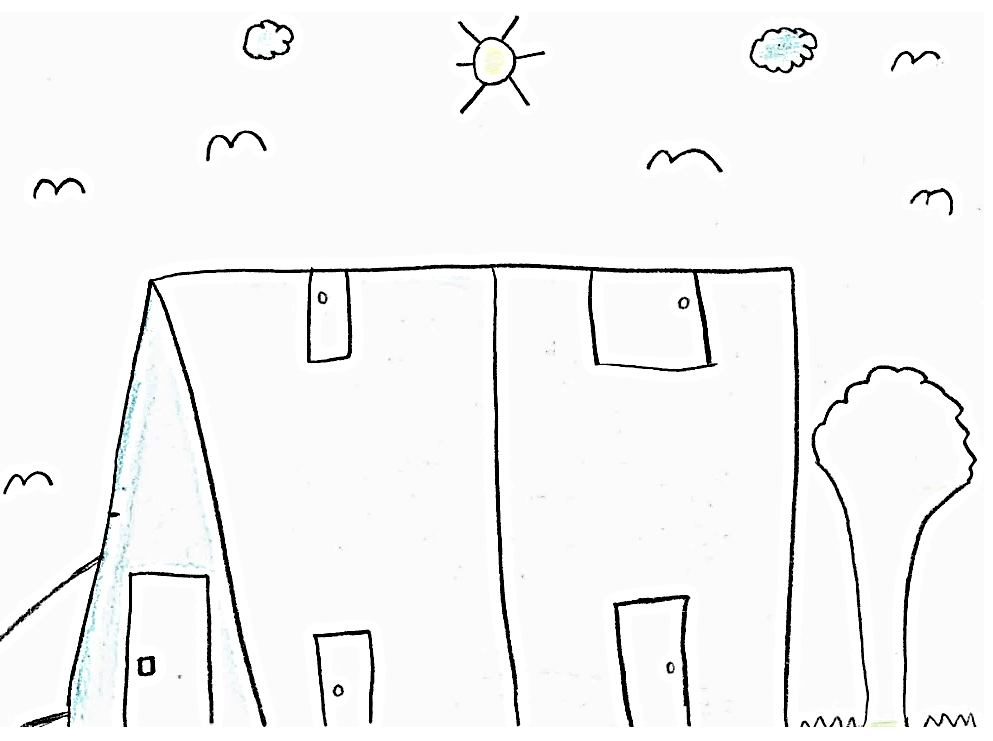

FONTE: acervo da pesquisa realizada.

Alguns elementos novos estão presentes, como as seis gaivotas, dando movimento e vivacidade à imagem. Fabíola pinta sua escola de azul. Nota-se traços e formatos geométricos e temática infantilizada, se considerar que se trata de um desenho de uma garota de 14 anos: "Minha escola é toda azul. Está escrito o nome dela lá e tem uma árvore perto" (Fabíola). Sobre a elaboração 
da estória, Fabíola teve um tempo de latência, pensando em possíveis temáticas. Fabíola verbalizou que gostava muito da quadra e então começou sua estória. O título da estória dado pela aluna foi "As Pimentadas":

Era uma vez que eu estava na escola. Fui jogar futebol com os meninos. Aí o menino tinha namorada e eu não sabia que os dois estavam namorando. Ai ele foi e me deu um beijo no rosto. Nós estávamos na quadra, jogando futebol. A menina ficou com ciúme e veio bater em mim. Ela bateu e eu bati nela. E ai o menino tentou separar. Eu não bati nela, mas ela chegou a bater em mim. Ai todos os meninos bateram nela, para ela parar de me bater. O diretor foi lá e brigou com a gente. Deu ocorrência, mas não foi para a mãe, ficou só lá, marcado o que nós fizemos. Eaté hoje nós não vamos mais brincar na quadra. Agora eu estou brincando. É isso. (Fabíola).

Com a estória contada por Fabíola, fica clara a dicotomia presente no início de sua adolescência. A infantilização aparece com o "Era uma vez", como se fosse um conto de fadas. De outro lado, traços de erotização, como um beijo, ser desejada por um menino, tendo todos os outros a defendendo e o título, "As Pimentadas", fazem referência ao despertar da sexualidade própria de seu período vital. Apesar de ser uma estória, a aluna contou sem interrupção, dando a impressão de tratar-se de um evento real. Comenta ao final que ela e os outros alunos tiveram uma advertência verbal por conta da briga. De qualquer forma, a estória mostra um relato de um acontecimento corriqueiro, não sendo identificado nada que mostre inadequação da aluna em seu ambiente decorrente de sua DI. Muito pelo contrário, Fabíola participa das aulas e tem amizades e inimizades na escola por conta de outros motivos que não a deficiência intelectual. Após o término da estória, Fabíola falou sobre a escola, dizendo que não gosta da comida de lá, porque "não tem gosto e é gelada". E afirmou que o que gosta na escola "é só a quadra, as professoras e o diretor. Ele brinca com a gente" (Fabíola).

A análise dos dados revela que, para os alunos participantes da pesquisa, as duas formas de escolarização são concebidas de formas realmente distintas: uma, como uma oportunidade para a realização de atividades lúdicas, contato com a natureza, brincadeiras, passeios, oportunidade profissional; a outra, como um local de aprendizagem acadêmica estruturada. Apesar de gostarem do aspecto lúdico e do acolhimento da escola especial, a maioria dos alunos revelou o desejo de frequentar a escola comum, visto que, em suas concepções, essa é a única que pode lhes ofertar o tão sonhado "aprender a ler e escrever". Tais achados corroboram com os dados da pesquisa de Dias (2012), na qual professoras e 
alunos apontaram o caráter lúdico presente no atendimento especial, mas não o acesso aos conhecimentos disciplinares.

Os dados obtidos, através da participação dos alunos, ratificam a necessidade de investigar suas concepções sobre suas escolas. São poucos os estudos que como este se dedicam a isso, talvez por conta da dificuldade de coleta e análise dos dados. Pode-se citar como exemplo de pesquisa que investigou a concepção de alunos com DI sobre a inclusão escolar Veltrone (2008) que se vale da análise de desenhos com dez alunos com DI, sendo nove egressos de classes especiais, um de escola especial e dez colegas de classe. A análise dos dados apontou que os alunos com DI que estudavam na escola comum sentiam-se, de alguma forma, excluídos socialmente e/ou academicamente, manifestando por meio dos desenhos apresentarem dificuldades para aprender o conteúdo visto na escola comum e, em sua maioria, atribuíram a si mesmos a culpa por isto. Para a autora, o grande desafio da escolarização em ensino comum é "prover situações pedagógicas que de fato possibilitem que todos os alunos sejam satisfatoriamente atendidos" (VELTRONE, 2008, p. 104). Outras pesquisas se propuseram a dar voz aos alunos com DI (CARNEIRO, 2007; DUARTE, 2008), ambas por meio de entrevistas com alunos com Síndrome de Down.

Os alunos afirmaram que não tiveram conhecimento prévio sobre a mudança de escola e suas implicações: troca de professores, amigos e ambiente, assim como na pesquisa de Dias (2012) que demonstrou que os alunos muitas vezes não sabem o motivo da transferência e porque devem frequentar serviços como o AEE (DIAS, 2012). No estudo de Antunes (2012), ao relatarem sobre suas vidas, os jovens com DI enfatizaram histórias de reprovação, o isolamento em sala de aula, a ausência de apoio às suas necessidades específicas e a falta de atenção a fatores como sexualidade e participação no mercado de trabalho. Tal aspecto é verificado na presente pesquisa com maior ênfase na participação de Fábio e Fabíola. Logo, em nenhum dos casos foi realizado um trabalho de preparo para a transferência e adaptação com provisão de suportes para os alunos em seu novo ambiente escolar. Assim como Saulo, Sofia não pode despedir-se de colegas e professores, pois sua transferência ocorreu à revelia da opinião de seus familiares. Essa mudança também fez com que a criança apresentasse comportamento instável, desatenção e inquietação na nova escola.

O bullying, em relação às dificuldades de aprendizagem apontado pelos participantes da pesquisa de Moscardini (2011) e Carneiro (2007), pode ser visto na pesquisa. Para Fábio, a transferência escolar lhe trouxe benefícios, como a possibilidade de conviver em um ambiente diferenciado, onde todos o compreendiam e onde encontrou parceiros nos colegas de sala e professores. As piadas e zombarias em relação à sua passividade e dificuldade de aprendizagem chegaram ao fim. Contudo, os tempos no ensino regular deixaram marcas, a 
timidez excessiva e a dificuldade para se relacionar, conforme apontado por outras pesquisas (MENDES; CAPELLINI, 2007; ANTUNES, 2012). Por último, Fabíola parece ter aprovado a transferência escolar. Para a aluna, a mudança de escola foi vista como parte inerente de um processo que aconteceria naturalmente. Para a aluna, o crescimento físico e o amadurecimento típico da adolescência implicariam na troca de escolas. Como apontado por Duarte (2008), os dados da presente pesquisa elucidam que mesmo com a garantia de direitos, os alunos com DI continuam enfrentando dificuldades no processo de inclusão escolar, seja de ordem afetiva, seja de efetivação das políticas e provisão de suportes ao processo de inclusão escolar.

\section{Considerações finais}

Como visto, dúvidas e dissensos em relação à inclusão escolar estão presentes no ambiente escolar, porém, é de primeira importância atentar que todo esse processo envolve um sujeito, o aluno, que é o maior interessado em seu processo de escolarização, seja na escola comum, seja na especial. Considerar suas emoções, sentimentos e concepções sobre as formas de escolarização é o primeiro passo para inserir o aluno como sujeito ativo, propiciando sua participação e de sua família no processo de transferência escolar. Logo, é necessário que a atuação de todos os profissionais atuantes na escola considere a relação entre os alunos com seus pares na elaboração de práticas inclusivas, uma vez que, nos casos em questão, fica clara a influência das zombarias e do bullying na percepção dos alunos sobre suas escolas e sobre suas próprias potencialidades e capacidades de aprendizagem.

Concluindo, foi possível avaliar a importância na investigação de aspectos referentes à escolarização, decorrentes da transferência escolar com os próprios sujeitos, visto que a análise do conteúdo projetivo evocado, ou pelo desenho ou pelas questões-estímulo subsequentes, fizeram emergir as opiniões dos alunos sobre suas próprias trajetórias escolares. Quanto ao limite do estudo, atenta-se para o número pequeno de participantes por conta do delineamento metodológico escolhido, não permitindo generalizações, sugerindo-se novas pesquisas sobre essa temática com outros delineamentos metodológicos. Por fim, aponta-se que a ausência de literatura expressiva atual sobre o tema (últimos 5 anos) prejudica a interlocução entre pesquisas. 


\section{REFERÊNCIAS}

ANTUNES, K. C. V. História de vida de alunos com deficiência intelectual: percurso escolar, e a constituição do sujeito. 2012. Tese (Doutorado em Educação) - Faculdade de Educação, Universidade do Estado do Rio de Janeiro, Rio de Janeiro. 2012.

BRASIL. Ministério da Educação. Política Nacional de Educação Especial na Perspectiva da Educação Inclusiva. 2008. Disponível em: <http://portal.mec.gov.br/arquivos/ pdf/politica educespecial.pdf>. Acesso em: 25 maio 2012.

BRASIL. Decreto n ${ }^{0} 7.611$, de 17 de novembro de 2011. Dispõe sobre a educação especial, o atendimento educacional especializado e dá outras providências. Diário Oficial da União, Brasília, 2011.

BRASIL. Lei no 13.146, de 6 de julho de 2015. Institui a Lei Brasileira de Inclusão da Pessoa com Deficiência. Diário Oficial da União, Brasília, 2015.

CARNEIRO, M. S. C. Deficiência Mental como Produção Social: uma discussão a partir de histórias de vida de adultos com Síndrome de Down. 2007. Tese (Doutorado em Educação) -Universidade Federal do Rio Grande do Sul, Porto Alegre. 2007.

CUNHA, R.; ROSSATO, M. A singularidade dos estudantes com deficiência intelectual frente ao modelo homogeneizado da escola: reflexões sobre o processo de inclusão. $R e$ vista Educação Especial, v. 28, n. 53, p. 649-664, 2015.

DIAS, A. M. In(ex)clusão no serviço de atendimento educacional especializado (SAEDE) e no ensino regular: os dizeres de alunos com deficiência intelectual e baixa visão e de suas professoras. 2012. Dissertação (Mestrado em Educação) - Centro de Ciências da Educação, Universidade Regional de Blumenau, Blumenau. 2012.

DUARTE, M. Síndrome de Down: situação escolar no Ensino Fundamental e Médio na cidade de Araraquara-SP. 2008. Tese (Doutorado em Educação Escolar) - Faculdade de Ciências e Letras, Universidade Estadual de São Paulo, Araraquara. 2008.

GARCIA, E. S. A história escolar de alunos de classes especiais para deficientes mentais. Rede Saci, 2004. Disponível em: <http://saci.org.br/?modulo=akemi\&parame tro $=13361>$. Acesso em: 21 abr. 2014.

MATURANA, A. P. P. M.; MENDES, E. G. O cenário das pesquisas internacionais sobre a inclusão e escolarização do aluno com deficiência intelectual. Olh@res, Guarulhos, v. 3, n. 1, p. 168-193, 2015.

MENDES, E. G. A radicalização do debate sobre inclusão escolar no Brasil. Revista Brasileira de Educação, v. 11, n. 33, p. 387-405, 2006.

MENDES, E. G.; CAPELLINI, V. L. F. O ensino colaborativo favorecendo o desenvolvimento profissional para a inclusão escolar. Educere et Educare Revista de Educação, v. 2, n. 4, p. 113-128, 2007. 
MOSCARDINI, S. F. Trabalho docente com alunos com deficiência intelectual em salas comuns e no atendimento educacional especializado: análise do processo inclusivo. 2011. Dissertação (Mestrado em Educação Escolar) - Faculdade de Ciências e Letras, Universidade Estadual Paulista Júlio de Mesquita Filho, Araraquara. 2011.

OMOTE, S. A formação do professor em Educação Especial na perspectiva da inclusão. In: BARBOSA, R. L. L. Formação de educadores: desafios e perspectivas. São Paulo: Ed. UNESP, 2003. p. 153-169.

PALMA, D.; DIAS, T. R. S. Encaminhamento de aluno do ensino comum para um centro de educação especial em tempo de inclusão. In: ENCONTRO DE PESQUISA EM EDUCAÇÃO DA REGIÃO SUDESTE, 6., Belo Horizonte, 2005. Anais... ANPEd, 2005. p. 1-15.

PLETSCH, M. D.; GLAT, R. A escolarização de alunos com deficiência intelectual: uma análise da aplicação do Plano de Desenvolvimento Educacional. Linhas Críticas, Brasília, v. 18, n. 35, p. 193-208, 2012.

SPINK, M. J. Linguagem e produção de sentidos no cotidiano. Rio de Janeiro: Centro Edelstein de Pesquisas Sociais, 2010.

TRINCA, W. Formas compreensivas de investigação psicológica: procedimento de desenhos-estórias e procedimentos de desenhos de família com estórias. São Paulo: Vetor, 2013.

VELTRONE, A. A. A inclusão escolar sob o olhar dos alunos com deficiência mental. 2008. Dissertação (Mestrado em Educação Especial) - Centro de Educação e Ciências Humanas, Universidade Federal de São Carlos, São Carlos. 2008.

Texto recebido em 06 de fevereiro de 2017.

Texto aprovado em 12 de março de 2017. 